\title{
Analysis of home support and ventilator malfunction in 1,211 ventilator-dependent
} patients

\author{
M. Chatwin, S. Heather, A. Hanak, M.I. Polkey and A.K. Simonds
}

ABSTRACT: Risk management is an important aspect of home ventilation (HV). We examined the nature of calls to a home support helpline to identify patient/equipment problems and strategies to minimise risk for patients, healthcare teams and manufacturers.

From 1,211 adult and paediatric patients with neuromuscular disease, chronic obstructive pulmonary disease or chest wall disease receiving $\mathrm{HV}$, all calls to a dedicated respiratory support telephone hotline between January 1, 2006 and June 30, 2006 were analysed.

1,199 patients received noninvasive ventilation, 12 tracheostomy ventilation; 149 had two ventilators for 24-h ventilator dependency. There was a mean of $\mathbf{5 2 8}$ daytime calls per month and 14 calls a month at night. Following 188 calls, a home visit was performed; these identified a technical problem that could either be solved in the patient's home in $64 \%$ or required replacement or new parts in $22 \%$ of cases. In 25 calls in which no mechanical fault was identified, 13 patients were either found to be unwell or required hospital admission.

Patients using HV have a substantial requirement for assistance, with most technical problems being resolved simply. Where no fault can be found during an equipment check, the patient themselves may be unwell and should receive early clinical evaluation. The patient may have mistaken clinical deterioration for an equipment problem.

KEYWORDS: Neuromuscular disease, noninvasive ventilation, respiratory failure, tracheostomy ventilation, ventilator failure

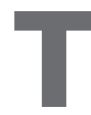
he topic of ventilator breakdown and adverse events in patients receiving home ventilation $(\mathrm{HV})$ has received little attention, which is surprising considering $\mathrm{HV}$ is a rapid area of growth and there is an increasing focus on risk management. SRINIVASAN et al. [1] examined ventilator- related problems in a group of patients in the USA, the majority $(76 \%)$ of whom were receiving tracheostomy ventilation. They reported 189 ventilator problems in $150 \mathrm{HV}$ users over a $1-y r$ period. $39 \%$ were due to defective ventilatory equipment or mechanical failure; in 30\%, equipment was improperly used by carers, and $13 \%$ were due to improper care or damage to equipment. $3 \%$ occurred due to a change in the patient's condition that required a change in ventilator setting and, in $16 \%$ of reported events, no problem with the equipment or ventilator was found. To resolve the problem, the ventilator was replaced in $44 \%$ of cases. Interestingly, $14 \%$ of these replacements were primarily to reassure the patient and carer, as no fault was identified. Hospitalisation was required in only $1 \%$ of the reports. It should be noted that this predominantly invasively ventilated population differs considerably from groups receiving (NIV) predominates [2].

There are, however, anecdotal reports of serious problems. LECHTZIN et al. [3] described a US patient with motor neurone disease/amyotrophic lateral sclerosis who had initially responded well to NIV, but there was no associated progressive care plan as he became more ventilator dependent. He died suddenly at home. The ventilator alarm log showed power failure was the cause, with no evidence of ventilator malfunction. No $\mathrm{HV}$ in Europe where noninvasive ventilation

For editorial comments see page 243.

Earn CME accreditation by answering questions about this article. You will find these at the back of the printed copy of this issue or online at www.erj.ersjournals.com/misc/cmeinfo.dtl

\section{AFFILIATIONS}

Academic and Clinical Dept of Sleep and Breathing, Royal Brompton Hospital, London, UK.

\section{CORRESPONDENCE}

M. Chatwin

Sleep and Ventilation Unit Royal Brompton Hospital

Sydney Street

London

SW3 6NP

UK

E-mail: m.chatwin@rbht.nhs.uk

Received:

May 062009

Accepted after revision:

July 232009

First published online:

July 302009 
battery back-up was available. A similar case of a ventilatordependent patient dying during a power cut has been reported in the UK [4].

The landmark Eurovent [2] study investigated the provision of HV across the European Union. As part of this survey, FARRÉ et al. [5], examined the quality control of home mechanical ventilation equipment and care packages. Considerable differences in patterns of care were identified between countries. Some hospital teams continued to supervise care in the home; in other countries, either dedicated regional home care organisations or commercial home care providers were employed. Regular servicing was carried out by external companies in $62 \%$ of centres. Communication between hospital and home care providers was variable. $72 \%$ of hospitals reported being informed of equipment problems, but only $61 \%$ of hospitals were always informed of major incidents. Unlike reporting of adverse reactions to drugs, there was also a lack of knowledge about where to report adverse events that had occurred with ventilatory equipment.

From a medico-legal perspective, the care and maintenance of ventilatory equipment in the home is normally the responsibility of the prescriber unless that role has clearly been handed over to another party. As the hospital usually retains clinical responsibility for the patient, communication between teams is vital. LLOYD OWEN et al. [2] demonstrated that patterns of quality control in HV in Europe vary, at least in part, as there are no well-established guidelines. The first aim of our study was to analyse ventilator malfunction in the patient's home. The second aim was to assess the calls received by a telephone support line from a large, mixed adult and paediatric population provided with $\mathrm{HV}$ by a regional centre.

\section{METHODS}

Our centre has provided HV since 1983; as patient numbers have grown, so has the service to support ventilator-dependent individuals both in hospital and at home. Patients are usually referred to our centre either via their general practitioner (GP) or via a consultant from their local hospital. The service provided is part of the National Health Service, meaning it is free and open to anyone. Initially the service consisted of one technician and one respiratory consultant physician. During the current evaluation, the respiratory support team consisted of two respiratory consultant physicians, two trainee doctors, five respiratory support-allied health professionals (including one clinical nurse specialist) and one administrative coordinator. Working hours were $09.00-17.00 \mathrm{~h}$ Monday to Friday; any calls or support needed outside these hours was viewed as an oncall/emergency service. After $17.00 \mathrm{~h}$, an emergency telephone line was answered by the NIV ward nursing staff (a rotating mix of four nurses), all of whom were trained in dealing with NIV problems. All telephone calls were charged at a local rate.

At initiation of $\mathrm{HV}$, all patients were reviewed by the respiratory consultant physician, who confirmed indications for treatment and determines the ventilatory regime. Patients using NIV were fitted with a mask interface and initially acclimatised to the ventilator at appropriate settings during the day [6]. We have previously reported that in-patient initiation of $\mathrm{HV}$ takes a mean $\pm \mathrm{SD}$ of $3.8 \pm 1.0$ days and outpatient between one and two sessions [7]. The ventilator was set up so that the pressure or tidal volume ensured a comfortable but adequate thoracic expansion and reduction in accessory muscle activity. Settings were further titrated after overnight monitoring of arterial oxygen saturation and transcutaneous carbon dioxide levels, and mask fit reviewed. All our HV patients undergo a educational programme to minimise the risk of adverse events as previously reported [8]. This is to ensure that patients and carers are competent in assembling the circuitry and are able to fit the mask and headgear effectively. Pre-discharge patients or the main carer were assessed following key competency areas, which are covered in the educational programme (table 1). Patients are discharged home with education packs; these included written material developed in the unit. This material was personalised to the individual to include mask and ventilator information and includes the patient's degree of urgency (DOU; level of priority) if equipment failure occurs and provides contact telephone number and information about our external service and maintenance company. Refresher education is provided at clinic visits and during in-patient readmissions.

At our centre, we use an external service and maintenance company (Smiths Medical, Watford, UK); this company services all ventilators according to manufacturer's guidance (usually annually) in the patients' home. Patients are classified as a onenight DOU (one DOU, i.e. able to function for either part of one night or one full night off ventilation), two DOU (able to function for two nights without ventilatory support) and as three DOU (able to function for three nights) in order for the service and maintenance company to prioritise their callouts. Once a fault has been identified, the external service and maintenance company are called. The external service and maintenance company immediately call the patient to acknowledge they have been notified and arrange to repair the ventilator in the patient's home within the patient's DOU. If the problem cannot be resolved, the external service and maintenance company technicians aim to either fix the equipment or replace it with an identical ventilator model at prescribed settings. If there are any medical matters arising, the technicians from the external service and maintenance company will call the team at the Royal Brompton Hospital, London, UK, explaining the situation, and advice is given to the patient. If it is the case that equipment is required, they will also notify the Brompton team and this will be sent out. At the end of each month, summary information is reported to us, and this includes the type of ventilators that are breaking down and a summary of each visit.

Between the start of January 2006 and the end of June 2006, demographic data was collected from the Royal Brompton Hospital patient database. This is an ongoing service and patients are registered on the database when they are discharged from hospital with HV. Over the 6-month period, we were responsible for providing $\mathrm{HV}$ to 1,211 adult and paediatric patients; diagnosis, age of commencement of $\mathrm{HV}$, whether the patients were receiving tracheostomy intermittent positive pressure ventilation or NIV, how many ventilators were provided per patient, and the level of ventilator dependency were recorded.

We prospectively manually entered into a database the number of telephone helpline calls we received within a 6month period from our 1,211 patients. This was subdivided 


\section{TABLE 1 Key competency areas for use of noninvasive ventilation (NIV) equipment}

1) Basic information includes: why the patient requires NIV, the degree of ventilator dependency (how long they can safely manage without their ventilator if it malfunctions), the purpose of alarms, servicing and maintenance plans, who to contact if the ventilator breaks down and how to order spares for the equipment (masks, tubing, filters, etc.).

2) Practical aspects. Patients must be able to turn the ventilator on and off, put the mask on and off, and assemble mask and headgear after washing. They must also demonstrate that they can change the circuit, and lock and unlock the ventilator if they need to change settings with instructions over the phone.

3) Technical information. We also ensure that each patient knows the precise model of their masks and ventilator and have received standard information, including the manufacturer's handbook, the correct telephone numbers to re-order spares, and the emergency helpline number for ventilator breakdown or problems.

4) Additional, more complex competency training is provided for patients with a tracheostomy and their carers/families. This includes training in tracheostomy tube changing and care, use of suction machines, heated humidification and problem-solving, e.g. dealing with blocked or displaced tubes (this is beyond the scope of this paper). Tracheostomy intermittent positive pressure ventilation patients frequently have a high level of ventilator dependency and therefore require back-up ventilators, suction machines, etc.

into calls received between $09.00 \mathrm{~h}$ to $17.00 \mathrm{~h}$, Monday to Friday; the calls were taken by four respiratory support-allied healthcare professionals who were trained in $\mathrm{HV}$, with three having a physiotherapy background; these individuals are dedicated to the home mechanical ventilation programme. The respiratory support-allied healthcare professionals triaged the calls and notified the respiratory physicians if they suspected a medical problem; this was followed up by the doctors and, if an equipment problem was suspected, the external service and maintenance company was contacted. The other group we evaluated comprised calls made to our on-call/emergency telephone helpline, which was also recorded in a database. The emergency helpline number is answered by nursing staff on a ward dedicated to $\mathrm{HV}$. If the nursing staff was unable to resolve or triage the problem, back-up advice was available from a dedicated NIV respiratory support-allied healthcare professional on call (fig. 1). We evaluated details of the reports to the emergency helpline number from all patients. We also recorded information during the 6-month period from the external service and maintenance company on nature of the emergency visits for ventilator breakdown, the faults identified and remedial measures taken.

All patients who were stable after initiation on home mechanical ventilation were seen after 3 months at the outpatient clinic. Depending on the severity and progression of the disease, patients were then seen at 3-9-monthly intervals. As our HV population lived in widely dispersed areas of England and Wales, our medical team carried out few home visits $\left(<2 \cdot\right.$ month $\left.^{-1}\right)$. After each clinic visit or hospital admission, the GP and referring centre received a letter documenting treatment and contact information. If there was a reason why this information needed to be communicated urgently, the letter was faxed to the centre and one of the doctors on the team would telephone the local physician. All home visits relating to this study were carried out by our external service and maintenance company's technicians. The hospital-based medical team liaised with the patient's GP after each clinic visit by letter and, if the hospital-based team identified a potential deterioration in the patient's condition, they would request that the GP carried out a home visit to assess the situation.

\section{RESULTS}

Between January 1, 2006 and June 30, 2006, we were responsible for 1,211 adult and paediatric patients (642 male and 589 female) receiving HV. For every 121 patients there is one member of staff. Patents had been using HV for between 3 months and $>15$ yrs. The mean age at treatment was $46 \pm 21$ yrs, and age range was 3 months to 87 yrs. Diagnoses for the patient population by age groups are shown in fig. 2 . Our respiratory support team (four respiratory support-allied healthcare professionals and one coordinator) received an average of 528 daytime calls per month lasting a mean \pm SD of $4.5 \pm 6.9 \mathrm{~min} .63 \%$ of calls were received in the morning and $37 \%$ in the afternoon. Only $3 \%$ of repeat calls received in daytime working hours were about the same query. $1 \%$ of 1,211 patients called outside working hours. 14 calls per month were to the on-call/emergency telephone helpline.

The level of ventilator dependency was determined by the patients/medical team at time of initiation of NIV and reassessed if the medical condition changed. $17 \%$ of patients were classified as a one DOU, $33 \%$ as a two DOU and $50 \%$ as a three DOU. 149 out of 1,211 (12.3\%) patients required two ventilators for 24-h or near-24-h ventilator dependency. As our NIV service began $>20$ yrs ago, our patients had ventilators made by a variety of manufacturers. 50\% used bi-level pressure preset ventilators; $48 \%$ had received single-level pressure preset ventilators and $2 \%$ used volume ventilators. $32 \%$ of patients had battery back up and $10 \%$ of patients had supplemental long-term oxygen therapy.

We examined in detail the 86 calls that were made to the oncall/emergency telephone support line. The average age of the patients was $53 \mathrm{yrs}$, with a range of 3-90 yrs. The number of calls were similar between the diagnosis groups when taking into the account of the total number of patients $(32 \%$ had neuromuscular disease (NMD) and two of these had motor neurone disease; $37 \%$ had chronic obstructive pulmonary disease (COPD); $15 \%$, obesity; $5 \%$, chest wall disease (CWD); $3 \%$, upper airway problems (tracheomalacia and craniofacial abnormalities, cerebral palsy and trisomy 21 ); and $8 \%$, other). $19 \%$ of the calls were from patients with a one night DOU, $10 \%$ with a two night DOU and $71 \%$ with a three night DOU. Onehalf (43 out of 86 ) of the calls were to report issues with the ventilator, but despite the education programme, the remainder of calls were nonurgent and did not fit the criteria for use of the emergency number, e.g. they were routine queries or requests for interfaces. Analysis of the nature of these calls is given in table $2.75 \%$ of calls related to suspected technical problems, e.g. alarms and ventilator not working, were made 


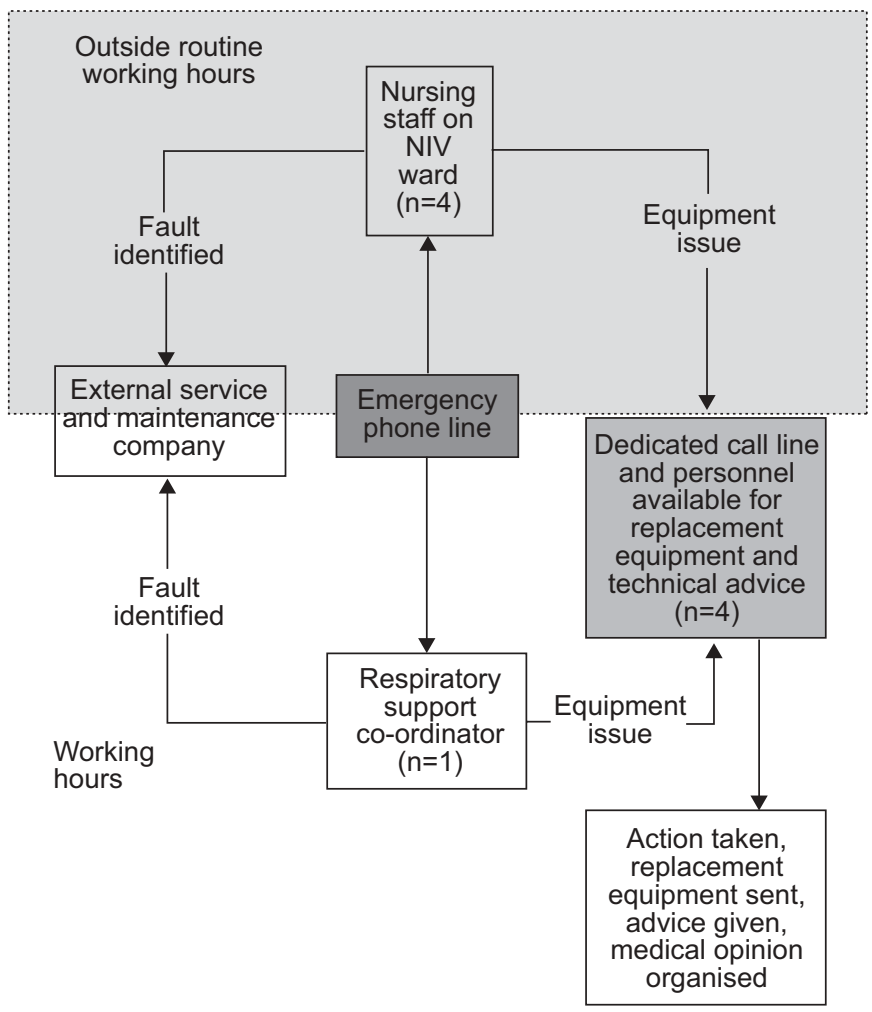

FIGURE 1. Flow chart showing the organisation of staff involved in answering the emergency phone line ( $\square$ ) and the dedicated line for replacement parts or technical advice ( $\square$ ) along with the number of staff involved (n). Out of hours organisation is shown in the top half of the figure and working hours in the bottom half. NIV: noninvasive ventilation.

because the patient/carer suspected there was a problem with the ventilator, and $25 \%$ of patients/carers telephoned as the ventilator had identified a problem, triggering an alarm. 16\% of the total number of calls was about a problem previously reported.

In the 6-month period, our external service and maintenance company carried out a total of 188 home visits because of ventilator or associated equipment-related problems that could not be diagnosed or solved by simple telephone advice. 41 out of the 188 home visits were requested after being reported to the emergency/on-call line. $32 \%$ of home visits were to NMD patients; $32 \%$, COPD; $14 \%$, CWD; $9 \%$, obesity; and $13 \%$, other. The mean age of this patient group was 52 (range 1-82) yrs. No home visits were required by patients using tracheostomy ventilation. Despite regular equipment servicing programme, in the 188 home visits, there was a technical problem with the equipment that was solved either in the patient's home in $64 \%$ of cases or by providing replacement equipment/parts in $22 \%$. Problems identified by the service and maintenance company in the patient's home are shown in table 3. All telephone calls were screened by the respiratory support-allied healthcare professionals team to ensure the problem was likely to be equipment malfunction and not a simple error, such as forgetting to plug in equipment or disconnection of circuit.

In $13 \%$ of home visits, no technical problem with the ventilator or circuitry was identified despite a detailed performance

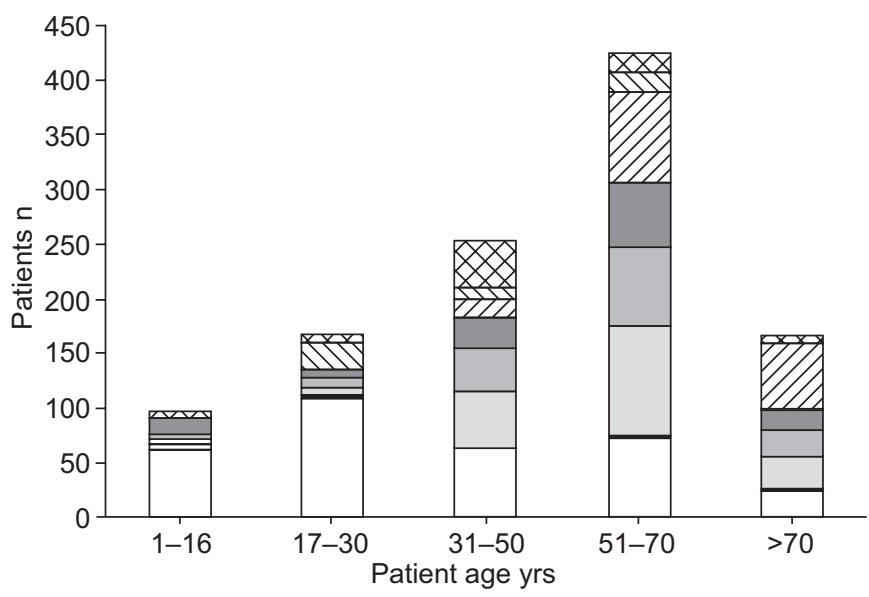

FIGURE 2. Graph showing the number of patients in various age groups and the number of patients per diagnosis. $\square$ : neuromuscular disease, including motor neurone disease; $\mathbf{\square}$ : central hypoventilation syndrome; 1 : obesity hypoventilation syndrome; 1 : chest wall disease; $\mathbf{m}$ : upper airway (tracheomalacia, craniofacial abnormality, cerebral palsy, trisomy 21 and $28 \%$ intolerant of autotitrating continuous positive airway pressure); $\square$ : chronic obstructive pulmonary disease $\nabla$ : bronchiectasis; $区$ : other (other diagnosis, including lung disease, e.g. pulmonary fibrosis).

check. Review of the circumstances of these episodes showed that in a total of 25 visits, no equipment fault was found. Of these, $32 \%$ involved COPD, $28 \%$ NMD, $24 \%$ CWD, $8 \%$ obesity and $8 \%$ bronchiectasis patients. The patient's DOU was as follows: one night, $28 \%$; two nights, $4 \%$; and three nights, $68 \%$. 13 out of 25 patients were unwell at home and/or required a

\section{TABLE 2 Calls to the emergency helpline out of hours over a 6-month period}

Out-of-hours calls $\mathbf{n}$

Total calls
Equipment required (tubing, filters,
mask spares)
Technical issue (included alarming,
not reaching pressure, noisy)
Ventilator not working
Advice: nonemergency
Advice about continuous positive
airways pressure
Advice: emergency
Battery not working
Request for servicing

\#: the patient should have called to request replacement consumables earlier $\because$ : the ventilator could be turned on but there were reports of it being noisy, an alarm going off such that the patient could not resolve the problem without telephone support, and the ventilator not giving the same size breath as the patient felt was normal for them; ${ }^{+}$: despite the power being connected, the ventilator did not start up; ${ }^{\S}$ : for example, the patient complained of mouth dryness. 


\begin{tabular}{|c|c|c|}
\hline \multirow[t]{2}{*}{ TABLE 3} & \multicolumn{2}{|c|}{$\begin{array}{l}\text { Reason for emergency visits over the 6-month } \\
\text { period }\end{array}$} \\
\hline & & Home visits $n$ \\
\hline \multicolumn{2}{|l|}{ Total visits } & 188 \\
\hline \multicolumn{2}{|c|}{ Ventilator not working } & 52 \\
\hline \multicolumn{2}{|c|}{ Technical issue (alarming, not reaching pressure, noisy) } & 43 \\
\hline \multicolumn{2}{|c|}{ Equipment required (tubing, filters, mask spares) } & 39 \\
\hline \multicolumn{2}{|l|}{ No fault } & 25 \\
\hline \multicolumn{2}{|c|}{ Circuit fitted incorrectly } & 9 \\
\hline \multicolumn{2}{|c|}{ Hospital requested exchange } & 9 \\
\hline \multicolumn{2}{|c|}{ Patient changed settings by mistake } & 8 \\
\hline \multicolumn{2}{|c|}{ Patient did not like replacement ventilator } & 2 \\
\hline \multicolumn{2}{|c|}{ Set up of ventilator at home } & 1 \\
\hline
\end{tabular}

hospital admission; two patients died within 1 month of an identification of "no fault". Both these patients died as a result of an acute exacerbation of COPD. Of the patients who were unwell at identification of "no fault", all had respiratory tract infections except one NMD patient who became more ventilatory dependent due to deterioration in respiratory muscle weakness. There was no association between acute infection as a cause of the reported problem and the level of ventilator dependency (i.e. having the highest ventilator dependency); $15 \%$ had one-night DOU and $85 \%$ had threenight DOU.

Analysis of ventilator breakdown rates adjusted for total number of ventilators in our service showed that there was an increased malfunction rate in ventilators that had been in service for $>8$ yrs, for example, the Respironics PLV 102 life care (Respironics, Murrysville, PA, USA), although no ventilator was used beyond the manufacturers' recommendations, and in ventilator models newly on the market. Importantly, there was also an increased equipment failure rate in highly ventilator-dependent patients (use $>16 \mathrm{~h} \cdot$ day $^{-1}$ ), suggesting that the number of failures is related to total hours of use. There was on average an $8 \%$ failure rate per manufacturer when the old and very new ventilators in service were included in the breakdown. The commonest causes of ventilator malfunction in our group of patients were motor blower or bellows failure, and circuit board ceasing to function. A large number of the alarm problems identified by external service and maintenance companies were as a consequence of water in a pressure line. This problem was resolved in some models by inserting a small filter.

\section{DISCUSSION}

The main finding of the present study is that patients have a substantial requirement for assistance with their ventilators at home. From our data, we expect each patient to make 5.5 telephone calls to the hospital per year and 3\% of these calls will be in the evenings and either at weekends or on public holidays. The majority $(78 \%)$ of home visits from the external service and maintenance company were as a result of daytime calls. From a risk-management viewpoint, no patient whose equipment required repair or replacement suffered adversely or required admission. However, we have identified a group of
HV users who reported a ventilator-related problem but no fault could be found during an equipment check conducted by an experienced engineer. Here, patient themselves is likely to be unwell and we would strongly recommend early clinical reevaluation after calls where no fault is identified. In this situation, it is likely that the patient has misinterpreted clinical deterioration for an equipment problem, or it is simply that due to changing pathophysiology, the ventilator settings no longer meet the patient's ventilator requirements.

In 2001, our centre had a similar diagnostic case mix to the Eurovent study: approximately one-third had NMD, one-third chest wall disease and the remaining one-third had COPD [2]. By 2006, the distribution receiving HV was as follows: NMD, $33 \%$; chest wall disease, $16 \%$; and COPD, $15 \%$. However, the proportion with obesity hypoventilation syndrome and other airways disease (bronchiectasis, cystic fibrosis) had increased. It is likely that, at the later date, there were fewer patients presenting with chest wall disease as a late effect of radical surgery for tuberculosis following the introduction antituberculous chemotherapy [9]. Our practice is in line with other countries in Europe with regard to servicing and maintenance of ventilatory equipment, as it is managed by an external company [5].

We identified two areas that contributed to ventilator breakdown rate: increased total hours of ventilator use and models new to the market. It is not surprising that ventilators used by patients for longer periods and those machines that are older will require earlier replacement of parts. However, when developing new ventilators, manufacturers need to be aware that problems may arise that were not identified on pre-market testing. In our study, we have specified neither the manufacturer nor model, as we issue feedback directly to the manufacturer who subsequently modifies the device and resolves the problem. Longer periods of bench testing of new machines by the manufacturer and the provision of spare units in anticipation of problems might be one solution for increased ventilator failure rates in new ventilators. Reporting to a central body on ventilator problems with certain devices is essential, and these data should be collated and disseminated as part of the medical devices directive. In the UK, adverse events are be reported to the Medicines and Healthcare Products Regulatory Agency (MHRA; www.mca.gov.uk). Manufacturers also need to ensure that alarms work appropriately. In our study, $75 \%$ of calls regarding equipment dysfunction were instigated because the patient or carer detected underperformance and not because an alarm was activated. Our data supports the work of FARRÉ et al. [10], who identified that ventilator alarms were not always available or set appropriately in patients using NIV.

Assessment of ventilator performance at home is required for patient safety; however, patients also need to be re-evaluated to ensure ventilator settings remain optimal. FARRÉ et al. [11] reported that the performance of a home mechanical ventilator in a patient's home can vary considerably. They found significant differences between actual, set and prescribed tidal volumes and respiratory rate. In order to reduce these discrepancies, they recommended that ventilators are serviced regularly to ensure quality control. Our centre adheres to this recommendation, however, there were still patients in whom 
additional home visits were required to assess the performance of the ventilator. We found mechanical ventilator failure rate to be relatively low, accounting for $28 \%$ of callouts to the home. This is similar to the ventilator failure rate reported by SRINIVASAN et al. [1]; however, a more frequent problem is the patient or carer not recognising that tubing or masks are damaged, despite a competency-based education programme. PLANT et al. [12] showed that it is more cost effective to set up NIV on a single ward that regularly carries out NIV setups rather than on different wards in the same hospital. They felt that this was attributable to training issues and retention of knowledge of staff. Equally, inconsistent patient education may cause an undue number of nonemergency callouts so that educational information needs to be regularly repeated and competency reassessed.

In $13 \%$ of the home visits, no fault with the equipment was found. In a previous study [1], when "no fault" was identified with the ventilator, two patients were hospitalised due to a change in their condition. Of our subgroup of 25 patients that reported ventilator problems but where none was identified, half were unwell either at home or in hospital and two died with in a month of the report of the problem. Patients may misinterpret a change in their health, e.g. an infective exacerbation, sputum retention, bronchospasm or pulmonary oedema, as the ventilator not working properly. Although they may well benefit from changes in the ventilator settings to deal with the pathophysiological change, e.g. increased airways resistance or reduced lung compliance, the underlying problem is with the patient, not the ventilator equipment, and further treatment may be urgently required. If these patients are then admitted to another hospital not familiar with ventilator use, healthcare professionals may also be quick to attribute the problem to equipment failure and be less likely to realise that there has been a primary change in the patient's health requiring active management, including secondary changes in ventilator settings. Thus, HV users who repeatedly call a telesupport line should not be labelled as "difficult" or "overanxious" if no technical malfunction can be found with their ventilator, circuitry or interface. These individuals need to have either an emergency clinic appointment and clinical assessment, or a home visit by the GP or medical team to prevent a potential adverse event as a consequence of deterioration in health. Education should be provided to new trainees about patients who call the helpline regularly so the most appropriate advice can be given, and to patients themselves to help them identify warning symptoms.

With the growing provision of home mechanical ventilation, service and maintenance is often carried out by external companies. Unlike some units [5], our centre receives regular feedback about ventilator performance and changes in settings, as well as more detailed information about the patient. We strongly advocate that centres have regular feedback about their patients to allow them to monitor and review them from afar, and identify new equipment problems. With the development of new technology [13] and improved telemedicine options [14, 15], even in very vulnerable patients [16], it is possible to download symptom scores, arterial oxygen saturation levels and ventilator performance details on tidal volume, pressure and leaks daily [14, 15]. Indeed, there are pilot studies in progress with some ventilators that are able to monitor pulmonary mechanics and adapt settings accordingly. If these advances are shown to be valid and cost effective, the logical next step in risk management is to identify those $\mathrm{HV}$ patients in whom this extra information may aid care, rather than extend extensive monitoring support indiscriminately to all HV recipients.

\section{Limitations}

This study is limited by the fact that we do not record the number of scheduled calls made to patients. Our centre does not provide routine home visits from doctors or the hospital-based team due to the wide geographical area that we cover. If a patient is identified who needs a medical review, we will ask the GP to review or arrange a home visit or an appointment at the GP's surgery to assess the patient. Despite immediate communication from the hospital to the community teams, some local professionals feel less able to cope with medical problems in ventilator-dependent patients, as they are anxieties about NIV, changing settings, etc. The availability of a team member who can visit patients and deliver support and education to the community teams would improve the community support that the hospital provides. Out of the 86 calls to the on-call emergency helpline number, only seven patients called twice, indicating that the potential problem could be remedied effectively. Only $1 \%$ of our subjects had motor neurone disease. We attribute this small number to the poor prognosis of this disease compared with other NMDs and the lack of neurology referrals, although this is improving. Other centres may have a greater number of patients with motor neurone disease and all these patients will need an evolving care plan and a greater amount of support compared with a more slowly progressive NMD. The upper airway disease group includes $28 \%$ who have failed autotitrating continuous positive airways pressure devices and have progressed to NIV. All paediatric and young adult patients in the upper airway group had tracheomalacia, trisomy 21, cerebral palsy or craniofacial abnormalities and, because of the common problem of upper airway collapse, they have been grouped together.

All members of staff are highly trained in HV and had experience of problem solving over a number of years; this skill mix might not be available in newly developed units. Despite the limitations of this study, we feel that our experience may be relevant to other centres providing $\mathrm{HV}$ and those planning a service.

In conclusion, there is a significant workload associated with supporting HV patients. Despite patients and carers receiving competency training before discharge, regular re-education is required and nonurgent other calls may be reduced by a more flexible problem-solving approach. Importantly, reports in which no technical fault is found may indicate deteriorating health in the patient and these individuals require close clinical re-evaluation.

\section{SUPPORT STATEMENT}

M. Chatwin has received educational grants from Breas Medical, Mölnlycke, Sweden and the Jennifer Trust for Spinal Muscular Atrophy, Stratford-upon-Avon, UK.

\section{STATEMENT OF INTEREST}

Statements of interest for M. Chatwin, M.I. Polkey and A.K. Simonds can be found at www.erj.ersjournals.com/misc/statements.dtl 


\section{ACKNOWLEDGEMENTS}

The authors would like to thank W. Sabado (Clinical and Academic Dept of Sleep and Breathing, Royal Brompton Hospital, London, UK) for his assistance in extrapolating data from the database.

\section{REFERENCES}

1 Srinivasan S, Doty SM, White TR, et al. Frequency, causes, and outcome of home ventilator failure. Chest 1998; 114: 1363-1367.

2 Lloyd-Owen SJ, Donaldson GC, Ambrosino N, et al. Patterns of home mechanical ventilation use in Europe: results from the Eurovent survey. Eur Respir J 2005; 25: 1025-1031.

3 Lechtzin N, Weiner C, Clawson L. A fatal complication of noninvasive ventilation. $N$ Engl J Med 2001; 344: 533.

4 Towlson S. Power cut kills man on home ventilator. The Times. London, UK, 2000; August 14.

5 Farré R, Lloyd-Owen SJ, Ambrosino N, et al. Quality control of equipment in home mechanical ventilation: a European survey. Eur Respir J 2005; 26: 86-94.

6 Chatwin M, Nickol AH, Morrell MJ, et al. Randomised trial of inpatient versus outpatient initiation of home mechanical ventilation in patients with nocturnal hypoventilation. Respir Med 2008; 102: 1528-1535.

7 Chatwin M, Heather S, Hanak A, et al. Analysis of emergency helpline support for home ventilator dependent patients: risk management and workload. Eur Respir Rev 2008; 17: 33-35.
8 Simonds AK. Risk management of the home ventilator dependent patient. Thorax 2006; 61: 369-371.

9 Mitchison DA. The diagnosis and therapy of tuberculosis during the past 100 years. Am J Respir Crit Care Med 2005; 171: 699-706.

10 Farré R, Navajas D, Prats E, et al. Performance of mechanical ventilators at the patient's home: a multicentre quality control study. Thorax 2006; 61: 400-404.

11 Farré R, Giró E, Casolivé V, et al. Quality control of mechanical ventilation at the patient's home. Intensive Care Med 2003; 29: 484-486.

12 Plant PK, Owen JL, Parrott S, et al. Cost effectiveness of ward based non-invasive ventilation for acute exacerbations of chronic obstructive pulmonary disease: economic analysis of randomised controlled trial. BMJ 2003; 326: 956.

13 Ishida R, Yonezawa Y, Maki H, et al. A wearable, mobile phonebased respiration monitoring system for sleep apnea syndrome detection. Biomed Sci Instrum 2005; 41: 289-293.

14 Chun H, Kang J, Kim K, et al. IT-based diagnostic instrumentation systems for personalized healthcare services. Stud Health Technol Inform 2005; 117: 180-190.

15 Vitacca M, Assoni G, Pizzocaro P, et al. A pilot study of nurse-led home monitoring for patients with chronic respiratory failure and with mechanical ventilation assistance. J Telemed Telecare 2006; 12 337-342.

16 Wilkinson OM, Duncan-Skingle F, Pryor JA, et al. A feasibility study of home telemedicine for patients with cystic fibrosis awaiting transplantation. J Telemed Telecare 2008; 14: 182-185. 